\title{
When Are Class I Metabotropic Glutamate Receptors Necessary for Long-Term Potentiation?
}

\author{
Volker W. Wilsch, ${ }^{1}$ Thomas Behnisch, ${ }^{1}$ Tino Jäger, ${ }^{1}$ Klaus G. Reymann, ${ }^{1,2}$ and Detlef Balschun ${ }^{1}$ \\ ${ }^{1}$ Leibniz Institute for Neurobiology, Department of Neurophysiology, and ${ }^{2}$ Research Institute of Applied Neurosciences \\ gGmbH, D-39008 Magdeburg, Germany
}

\begin{abstract}
The involvement of metabotropic glutamate receptors (mGluRs) in hippocampal long-term potentiation (LTP) is a matter of controversial debate. Using $\left[\mathrm{Ca}^{2+}\right]_{\mathrm{i}}$ measurements by confocal laser scanning microscopy and field recordings of EPSPs (fEPSPs) in the hippocampal CA1-region, we found that the efficacy of the broad-spectrum mGluR-antagonist (S)- $\alpha$-methyl-4-carboxyphenylglycine (MCPG) and of (S)-4carboxy-phenylglycine (4-CPG), a selective antagonist at class I mGluRs, in LTP is contingent on the tetanization strength and the resulting $\left[\mathrm{Ca}^{2+}\right]_{i}$ response. As indicated by experiments in which we blocked voltage-dependent cal-
\end{abstract}

The induction of long-term potentiation (LTP), an activitydependent form of synaptic plasticity, was proven to require the influx of $\mathrm{Ca}^{2+}$ through the NMDA type of glutamate receptors (NMDARs), under most experimental conditions (Bliss and Collingridge, 1993; Malenka, 1994). However, because an activation of NMDARs alone results in decremental short-term potentiation (Collingridge et al., 1983; Kauer et al., 1988), other mechanisms such as a coactivation of metabotropic glutamate receptors (mGluRs) have been suggested to be involved.

Until now, eight subtypes of mGluRs have been described and assigned to three different classes according to their sequence homology, pharmacological characterization, and coupling to second messenger pathways. While the activation of class I mGluRs (mGluR1, 5) stimulates phosphatidylinositol 4,5-bisphosphate hydrolysis [producing inositol 1,4,5-trisphosphate $\left(\mathrm{IP}_{3}\right)$ and diacylglycerol], mGluRs of class II (mGluR2, 3) and class III (mGluR4, $6,7,8$ ) are negatively coupled to adenylyl cyclase (Nakanishi, 1994; Conn and Pin, 1997).

The involvement of mGluRs in hippocampal synaptic plasticity has been a matter of controversial debate during the last few years. In particular, experiments using the class I/II specific antagonist $(S)-\alpha$-methyl-4-carboxyphenylglycine (MCPG) yielded conflicting results. While some authors reported an inhibition of LTP (Bashir et al., 1993; Bortolotto et al., 1994; Brown et al., 1994; RichterLevin et al., 1994; Little et al., 1995; Riedel et al., 1995), in other studies the MCPG actions could not be confirmed (Chinestra et al., 1993; Manzoni et al., 1994; Selig et al., 1995; Thomas and O’Dell,

\footnotetext{
Received Dec. 19, 1997; revised May 14, 1998; accepted May 27, 1998.

This research was supported by the Deutsche Forschungsgemeinschaft Sonderforschungsbereich 426. We thank Dr. Denise Manahan-Vaughan and Dr. Ritchie Brown for critical comments on this manuscript, and Ms. Katrin Böhm for excellent technical assistance.

Correspondence should be addressed to Detlef Balschun, Leibniz Institute for Neurobiology, Department of Neurophysiology, P.O. Box 1860, D-39008 Magdeburg, Germany.

Copyright (C) 1998 Society for Neuroscience $\quad 0270-6474 / 98 / 186071-10 \$ 05.00 / 0$
}

cium channels (VDCCs) and intracellular $\mathrm{Ca}^{2+}$ stores (ICSs), the functional significance of class I mGluRs in LTP is confined to certain types of potentiation, which are induced by weak tetanization protocols and require the release of $\mathrm{Ca}^{2+}$ from ICSs for induction. During strong tetanic stimulation, this $\mathrm{Ca}^{2+}$ source is functionally bypassed by activating VDCCs.

Key words: class I metabotropic glutamate receptors; longterm potentiation; intracellular calcium concentration; intracellular calcium stores; voltage-dependent calcium channels; hippocampus

1995). The issue of whether MCPG-sensitive mGluRs are involved in NMDAR-dependent synaptic plasticity was further confounded by the contrasting results of studies using mGluR1 and mGluR5 knock-out mice (Aiba et al., 1994; Conquet et al., 1994; Lu et al., 1997).

An intriguing possibility for resolving the controversy was provided by the "molecular switch hypothesis" (Bortolotto et al., 1994). According to this hypothesis, activation of mGluRs before LTP sets an input-specific molecular switch that then negates the necessity of further mGluR activation during LTP induction. However, other groups failed to confirm the existence of such a molecular switch (Selig et al., 1995; Thomas and O'Dell, 1995), giving a clear indication that the switch is not a general mechanism of synaptic plasticity but rather confined to certain experimental conditions.

Therefore, we pursued another idea to approach this question and focused on the effects of class I mGluRs on the $\mathrm{IP}_{3}$-mediated $\mathrm{Ca}^{2+}$ release from intracellular $\mathrm{Ca}^{2+}$ stores (ICSs) (Murphy and Miller, 1988; Berridge, 1993; Jaffe and Brown, 1994; Shirasaki et al., 1994; Phenna et al., 1995). Several laboratories have shown that the rise in intracellular $\mathrm{Ca}^{2+}$ concentration $\left(\left[\mathrm{Ca}^{2+}\right]_{i}\right)$ is a critical factor for LTP induction (Lynch et al., 1983; Malenka et al., 1988, 1992) and that the contribution of $\mathrm{Ca}^{2+}$ from ICSs may represent a critical factor for generating a long-lasting potentiation (Harvey and Collingridge, 1992; Behnisch and Reymann, 1995).

We suggest that this $\mathrm{Ca}^{2+}$ source should be particularly important under conditions where $\mathrm{Ca}^{2+}$ entry through NMDARs and voltage-dependent calcium channels (VDCCs) does not attain the threshold concentration for triggering subsequent transduction pathways that are critical for LTP maintenance.

\section{MATERIALS AND METHODS}

\section{Hippocampal slice preparation}

Hippocampal slices were prepared from male rats (7-8 weeks old) of the Wistar outbred strain MOL: WIST (SHOE). After decapitation and 

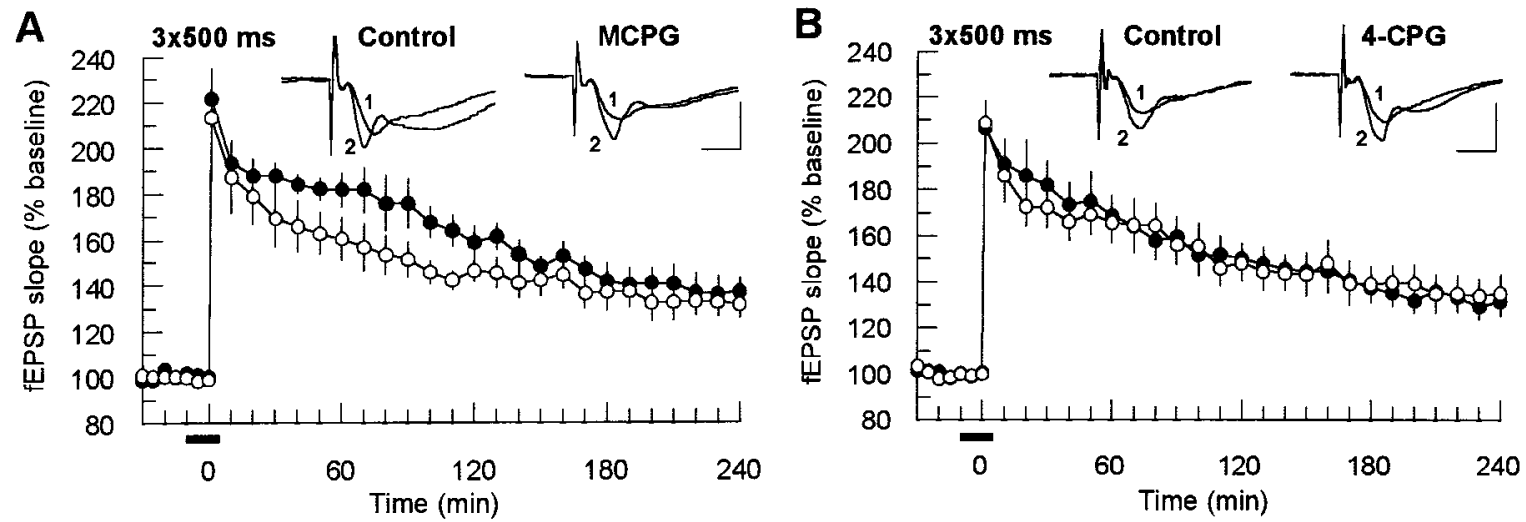

Figure 1. MCPG $(400 \mu \mathrm{M} ; n=7)(A)$ and $4-C P G(100 \mu \mathrm{M} ; n=7)(B)$ did not influence LTP induced by a strong tetanization $(3 \times 100 \mathrm{~Hz}, 500 \mathrm{msec}$, 2 min interval between trains). The potentiation persisted for at least $240 \mathrm{~min}$. The tetanus was applied at the time point 0 . Horizontal bars under the time scale indicate the time of drug application. Analog traces represent typical recordings of single experiments taken 10 min before tetanization ( 1 ) and $120 \mathrm{~min}$ after tetanization (2). $\mathrm{O}$, Drug-treated groups; $\bullet$, controls. Calibration: $2 \mathrm{mV}, 3 \mathrm{msec}$.

dissection of the hippocampus, $400-\mu \mathrm{m}$-thick slices were cut in cold oxygenated physiological solution [artificial CSF (ACSF) (in mM): $\mathrm{NaCl}$ 124, $\mathrm{KCl} 4.9, \mathrm{MgSO}_{4} 1.3, \mathrm{CaCl}_{2} 2.5, \mathrm{KH}_{2} \mathrm{PO}_{4} 1.2, \mathrm{NaHCO}_{3}$ 25.6, D-glucose 10 , saturated with $95 \% \mathrm{O}_{2}, 5 \% \mathrm{CO}_{2}, \mathrm{pH}$ 7.4] using a tissue chopper. The slices were submerged and permanently perfused with $32^{\circ} \mathrm{C}$ ACSF.

\section{Electrophysiological long-term recordings}

Synaptic responses were elicited by stimulation of the Schaffer collateralcommissural fibers in stratum radiatum of the CA1 region using lacquercoated stainless steel stimulating electrodes. Glass electrodes (filled with ACSF, 1-4 M $\Omega$ ) were placed in the apical dendritic layer to record field EPSPs (fEPSPs). The initial slope of the fEPSP was used as a measure of this potential. The test stimulation strength was adjusted to $35 \%$ of the maximum. During baseline recording, four single stimuli $(10 \mathrm{sec}$ interval) were averaged every $5 \mathrm{~min}$. After tetanization, recordings were taken every $10 \mathrm{~min}$ over a period of at least $120 \mathrm{~min}$. Once a stable baseline had been established, LTP was induced by one of the following tetanization paradigms.

Strong tetanization. Three trains of $500 \mathrm{msec}$ duration at $100 \mathrm{~Hz}$ and 0.2 msec pulse width, separated by 2 min intervals, induced a stable potentiation of fEPSP of at least $180 \mathrm{~min}$ in control experiments.

Weak tetanization. (1) Four paired pulses (10 msec interval, $0.2 \mathrm{msec}$ pulse width) were applied at the theta frequency of $5 \mathrm{~Hz}$. The tetanization was strengthened either by adding two more paired pulses up to eight $\times$ two pulses or further by increasing the number of pulses (eight $\times$ four). (2) A single train of $400 \mathrm{msec}$ duration at $100 \mathrm{~Hz}$ and $0.2 \mathrm{msec}$ pulse width was applied. These weak tetanization protocols triggered a potentiation that returned to baseline level within $180 \mathrm{~min}$.

In some experiments, two independent pathways were stimulated in the same slice by placing the stimulation electrodes symmetrically to the recording electrode into the apical dendritic layer at a different distance from the pyramidal layer.

The mGluR antagonists MCPG and ( $S$ )-4-carboxyphenylglycine (4$\mathrm{CPG}$ ) (Tocris, Bristol, UK) were dissolved in ACSF and bath-applied from 10 min before until 5 min after tetanization. Thapsigargin (Calbiochem, Bad Soden, Germany), a potent and selective inhibitor of intracellular $\mathrm{Ca}^{2+}$ pumps, and the L-type VDCC blocker nimodipine (Sigma, Deisenhofen, Germany) were initially dissolved in dimethylsulfoxide (DMSO) and further diluted with ACSF (final concentration of DMSO $<0.01 \%$ ). Thapsigargin was added to the bath from $30 \mathrm{~min}$ before until 5 min after tetanus; nimodipine was added according to the same time schedule as MCPG and 4-CPG. The drugs were applied either alone or in combination, as indicated in the text. All solutions were adjusted to $\mathrm{pH}$ 7.4. For statistical analysis, the Mann-Whitney $U$ test (independent samples) and the Wilcoxon matched pairs signed rank test were used with a significance level of $p<0.05$.

\section{Confocal microscopy}

Experiments were performed on ventral transverse hippocampal slices (250 $\mu \mathrm{M}$ thick) from 20-d-old male Wistar rats in the same solutions and conditions as the extracellular experiments.
Pyramidal CA1 neurons and their $\mathrm{Ca}^{2+}$ transients were visualized with a Odyssey XL confocal laser scanning microscope (Noran Instruments, Middleton, WI) mounted on an Axioskop-FS upright microscope (Zeiss, Jena, Germany). Image acquisition was performed using Intervision software (Noran Instruments) on a Silicon Graphics Indy workstation. All recordings were performed with a $488 \mathrm{~nm}$ excitation filter and a $515 \mathrm{~nm}$ long-pass emission filter. The slit aperture on the photomultipliers set was adjusted to $100 \mu \mathrm{m}$ width. A $40 \times$ water-immersion objective $(\mathrm{NA}=0.75)$ was used to visualize neurons.

CA1 pyramidal cells were impaled with potassium acetate $(2 \mathrm{M})$-filled borosilicate glass microelectrodes (80-150 M $\Omega$ ) (Clark, Pangbourne, UK). The tips of these sharp electrodes were filled with the $\mathrm{Ca}^{2+}$. sensitive dye Calcium Green-1 (2 mm; Molecular Probes, Leiden, Netherlands). For the experiments involving bath application of 4-CPG, and coapplication of 4-CPG and nimodipine, $30 \mathrm{~mm}$ QX-314 (Alomone Labs, Jerusalem, Israel) was added to the dye solution. A monopolar stimulating electrode was positioned in CA1 stratum radiatum. Only neurons with a membrane potential below $-55 \mathrm{mV}$ [recorded with an npi SEC 1L-amplifier (NPI Electronic, Tamm, Germany) at bridge-mode] were used. The electrophysiological properties of the neurons were controlled during the whole experiment. The dye was injected into the neurons by applying a steady-state hyperpolarizing current of $100-400 \mathrm{pA}$ for $15-20$ $\mathrm{min}$. Well stained, in focus dendrite regions $80-200 \mu \mathrm{m}$ from soma were chosen for recording the $\mathrm{Ca}^{2+}$ responses to different tetani. Tetanizations were performed in a time interval of 2 min with biphasic pulses. The changes in fluorescence intensity were averaged over $66.7 \mathrm{msec}$ (average of eight images). For data analysis, four regions of interest (ROI) were selected on the dendritic tree. The fluorescence intensities of these four ROI were averaged, and a background correction was performed, i.e., a nearby nonactive region of the same size as the recording region was measured in parallel and subtracted. The results were given as $F / F_{0}$ whereby $F_{0}$ was the averaged intensity before the tetanization.

\section{RESULTS}

Because most of the studies that addressed the functional role of mGluRs in LTP were performed in the CA1 region of the hippocampus, we recorded fEPSPs in the apical dendritic layer of this area by stimulating the Schaffer collateral-commissural fibers. The initial slope of the fEPSPs was used as a measure of synaptic responses. In the first series of experiments we tested whether the ability of mGluR antagonists to block LTP depends on tetanization strength. In the strong tetanization paradigm $(3 \times$ $100 \mathrm{~Hz}, 500 \mathrm{msec}, 2$ min interval between trains), which led to a stable potentiation lasting $>240$ min under control conditions, the application of MCPG $(400 \mu \mathrm{M})$ affected neither the initial magnitude (MCPG group: $213 \pm 12 \%, n=7$; control: $220 \pm 7 \%, n=$ 7) nor the time course of potentiation (after $240 \mathrm{~min}: 133 \pm 6 \%$ and $137 \pm 5 \%$, respectively) (Fig. $1 A$ ). Because MCPG is a broad-spectrum antagonist acting on class I mGluRs, and with a 

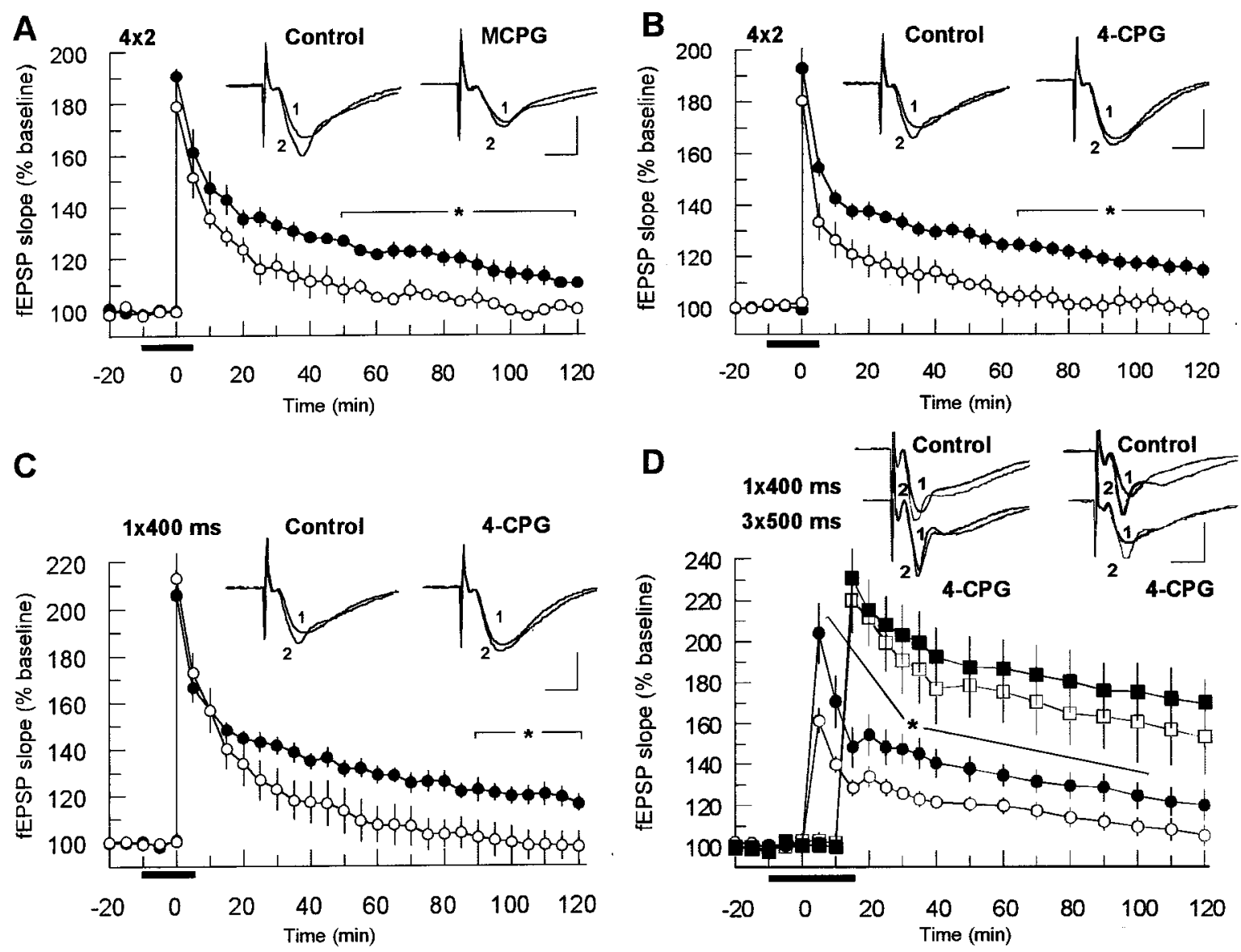

Figure 2. LTP induced by a weak tetanization protocol was susceptible to the action of MCPG $(A)$ or 4-CPG $(B-D)$. The tetanization consisted of either four $\times$ two pulses $(200 \mathrm{msec}$ interval between pulse pairs) $(A, B)$ or a single $100 \mathrm{~Hz}$ train, 400 msec duration $(C)$. In the experiments depicted in $D$, two independent pathways in the same slice were used to allow a direct comparison of the effects of 4-CPG on LTP generated by induction protocols of different strength. The groups treated with mGluR antagonists are indicated by open symbols, and their respective controls are indicated by closed symbols. A, Application of $400 \mu \mathrm{M}$ MCPG led to a significant reduction of LTP, starting at 50 min post-tetanus $(n=7$, as compared with controls, $n=$ 9; $p<0.05)$. $B$, 4-CPG $(50 \mu \mathrm{M})$ caused a significant blockade of LTP from 65 min after tetanus (4-CPG groups: $n=6$; controls: $n=8 ; p<0.05$ ). $C$, Similarly, an LTP induced by the weak $100 \mathrm{~Hz}$ tetanization decayed faster after application of 4-CPG (50 $\mu \mathrm{M})$. $D, 4-\mathrm{CPG}(50 \mu \mathrm{M})$ significantly impaired a decremental LTP that was induced by a weak tetanization (single $100 \mathrm{~Hz}$ train, $400 \mathrm{msec}$ duration; circles) of the first pathway, but had no significant effect on a robust potentiation $(3 \times 100 \mathrm{~Hz}, 500 \mathrm{msec}$ duration, 2 min interval between trains; squares $)$ generated 10 min afterward by strong tetanization of the second pathway. Note that in $D$ the first sampling time after tetanus was $5 \mathrm{~min}$, but it was $1 \mathrm{~min}$ in $A-C$. Analog traces represent typical recordings of single experiments taken $10 \mathrm{~min}$ before tetanization (1) and $60 \mathrm{~min}$ after tetanization (2). Calibration $2 \mathrm{mV}, 3 \mathrm{msec}$.

somewhat lower affinity at mGluRs of class II (Davies et al., 1995; Sekiyama et al., 1996), we repeated the same experiments with 4-CPG, which represents in the employed concentration range a specific antagonist toward class I mGluRs. 4-CPG $(100 \mu \mathrm{M})$ had no effect on the initial potentiation (4-CPG group: $208 \pm 9 \%, n=$ 7; control: $206 \pm 10 \%, n=7)$ and the maintenance of LTP (240 min after tetanus: $135 \pm 8 \%$ and $132 \pm 6 \%$, respectively) (Fig. $1 B)$. From these experiments, we concluded that activation of mGluR class I is not mandatory for the induction of a long-lasting potentiation by strong tetanization.

To test whether these drugs can affect a potentiation induced by a weak tetanic stimulation, we conducted experiments in which we used tetanization paradigms consisting of either four paired pulses (10 msec interval, applied at the theta frequency of $5 \mathrm{~Hz}$ ) or a single $100 \mathrm{~Hz}$ train of $400 \mathrm{msec}$ duration.

"Paired-pulse tetanization" induced an LTP that lasted $\sim 180$ min under control conditions. Application of $400 \mu \mathrm{M}$ MCPG did not influence the initial magnitude of potentiation (MCPG group: $179 \pm 6 \%$; control: $190 \pm 7 \%$ ) but significantly impaired the maintenance of LTP beginning 50 min after the tetanus $(n=$
$7 ; p<0.05$ ) (Fig. 2A). After $120 \mathrm{~min}$, the fEPSP potentiation of the MCPG-treated slices had returned to baseline values, whereas the control group was still above baseline $(110 \pm 2 \% ; n=$ 9). Similarly, application of $50 \mu \mathrm{M} 4-\mathrm{CPG}(n=6)$ led to a faster decline of LTP compared with control (from 65 min after tetanus) but left the initial potentiation untouched $(181 \pm 9 \% 4-\mathrm{CPG}$ experiments; $192 \pm 7 \%$ control) (Fig. $2 B$ ). The effect of $4-C P G$ on LTP induced by the weak $100 \mathrm{~Hz}$ tetanization resembled the effect observed in the previous tetanization paradigm, i.e., beginning 90 min post-tetanus, the potentiation of the 4-CPG group was significantly impaired $(102 \pm 6 \% ; n=6)$ as compared with control $(122 \pm 5 \% ; n=8)$ (Fig. $2 C)$.

To verify the actions of 4-CPG with a different experimental approach, we used two independent stimulation pathways in the same slice $(n=6)$. A weak tetanization was applied to the first pathway (single $100 \mathrm{~Hz}$ train, $400 \mathrm{msec}$ duration) followed $10 \mathrm{~min}$ afterward by a strong tetanization $(3 \times 500 \mathrm{msec}, 100 \mathrm{~Hz}, 2 \mathrm{~min}$ interval between trains) of the second pathway. 4-CPG $(50 \mu \mathrm{M})$ significantly impaired the decremental LTP that was induced by the weak tetanization (4-CPG group: $109 \pm 4 \%$; control: $124 \pm$ 


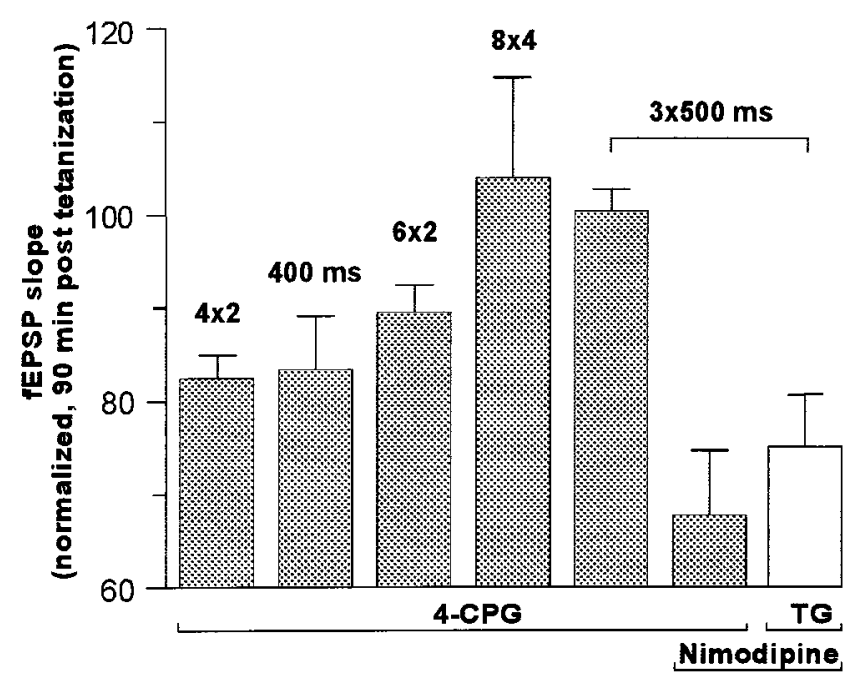

Figure 3. The effectiveness of 4-CPG on LTP was contingent on the strength of tetanization. The fEPSP slope potentiation (normalized to controls $90 \mathrm{~min}$ after tetanization) was mostly impaired using tetanization protocols of four $\times$ two pulses $(82.4 \pm 2.5 \%, n=7 ; p<0.05$; left column $)$ and $100 \mathrm{~Hz}, 400 \mathrm{msec}$ duration $(83.4 \pm 5.7 \%, n=5, p<0.05)$. The effect decreased if six instead of four paired pulses were applied in the pairedpulse protocol $(89.5 \pm 2.9 \%, n=5 ; p<0.05)$. Enhancement of the tetanus strength, by adding two more pulses $(8 \times 2)$ (data not shown) or by increasing the number of pulses $(8 \times 4)$ or by applying a strong tetanization of $3 \times 100 \mathrm{~Hz}(500 \mathrm{msec}, 2 \mathrm{~min}$ interval between trains) abolished the effect of 4-CPG on LTP $(103.9 \pm 10.6 \%, n=5$, and $100.4 \pm$ $2.3 \%, n=6$, respectively). Coapplication of 4-CPG $(100 \mu \mathrm{M})$ and nimodipine $(10 \mu \mathrm{M})$ resulted in a clear decrease of potentiation to $67.8 \pm 6.9 \%$ $(n=7)$. This effect could be mimicked by coapplication of thapsigargin $(T G)$ and nimodipine $(n=7)$.

$6 \%$, at $100 \mathrm{~min} ; p<0.05)$ but had no significant effect on the robust potentiation generated by the strong tetanization paradigm (4CPG group: $161 \pm 15 \%$; control: $174 \pm 14 \%$, at $100 \mathrm{~min}$ ) (Fig. 2D).

Because MCPG and 4-CPG were effective only in the weak tetanization paradigm, we investigated whether the efficiency of class I antagonists is dependent on the tetanization strength. To test this, the tetanization strength of the weak tetanization paradigm of four bursts of two pulses at $5 \mathrm{~Hz}$ was gradually increased by adding more bursts or by increasing the number of pulses per burst. The resulting fEPSP slope potentiation (normalized to controls 90 min after tetanization) was compared with the fEPSP slope potentiation that was obtained with the other tetanization protocols used in this study. The results depicted in Figure 3 (columns 1-5, left) clearly indicate that the 4-CPG effect is contingent on tetanization strength. The fEPSP slope potentiation was mostly impaired using tetanization protocols of four $\times$ two pulses $(82.4 \pm 2.5 \%, n=7 ; p<0.05$; left column $)$ and $100 \mathrm{~Hz}, 400$ msec duration $(83.4 \pm 5.7 \%, n=5 ; p<0.05)$. The effect decreased if six instead of four paired pulses were applied in the paired-pulse protocol $(89.5 \pm 2.9 \%, n=5 ; p<0.05)$. Enhancing the tetanus strength either by adding two more paired pulses (eight $\times$ two) (data not shown) and further by increasing the number of pulses (eight $\times$ four) or by applying a strong tetanization of $3 \times 500 \mathrm{msec}$ at $100 \mathrm{~Hz}$ ( 2 min interval between trains) abolished the effect of 4-CPG on LTP (eight $\times$ four pulses: $103.9 \pm$ $10.6 \%, n=5 ; 3 \times 500$ msec: $100.4 \pm 2.3 \%, n=6)$.

The experiments presented above showed that the effectiveness of MCPG and 4-CPG on LTP is confined to weak tetanization paradigms. Because it has been demonstrated that the magnitude of $\mathrm{Ca}^{2+}$ influx through NMDARs may be a critical factor in determining whether a robust or decremental potentiation is induced (Malenka et al., 1992), we suggested that the involvement of class I mGluRs in LTP may depend on the level and dynamics of $\left[\mathrm{Ca}^{2+}\right]_{\mathrm{i}}$ during tetanization. To examine how an increment of the duration of tetanization affects the rise of $\left[\mathrm{Ca}^{2+}\right]_{i}$ in dendrites, pyramidal CA1 neurons were loaded with the $\mathrm{Ca}^{2+}$. sensitive dye Calcium Green-1 and stimulated by a monopolar stimulating electrode positioned $80 \mu \mathrm{m}$ from soma in CA1 stratum radiatum. Tetanizations of different durations (and pulse widths) were applied in a time interval of $2 \mathrm{~min}$, and the $\mathrm{Ca}^{2+}$ responses of selected dendritic regions were visualized by confocal laser scanning microscopy and subsequently analyzed. As exemplified in Figure $4 A$, weak $100 \mathrm{~Hz}$ tetanization protocols (e.g., $200 \mathrm{msec}$, pulse width $0.1 \mathrm{msec}$ ) induced a submaximal, short-lasting rise of $\left[\mathrm{Ca}^{2+}\right]_{\mathrm{i}}$. Augmenting the pulse width or increasing the duration of tetanization advanced the $\left[\mathrm{Ca}^{2+}\right]$. response toward maximum values. After approaching these peak $\mathrm{Ca}^{2+}$ concentrations, any further extension of tetanization broadened the peak and slowed down the decay. For example, a $1 \mathrm{sec}$ train of $100 \mathrm{~Hz}$ caused an elevation of $\left[\mathrm{Ca}^{2+}\right]_{\mathrm{i}}$ that lasted for more than $2 \mathrm{sec}$. Application of a weak tetanization paradigm of four $\times$ two pulses at $100 \mathrm{~Hz}$ (200 msec interburst interval) triggered a $\left[\mathrm{Ca}^{2+}\right]_{\mathrm{i}}$ rise that resembled the $\left[\mathrm{Ca}^{2+}\right]_{\mathrm{i}}$ responses obtained with the common $100 \mathrm{~Hz}$ protocols but was superimposed by steep pinnacles that were synchronized with the interburst interval of $200 \mathrm{msec}(5 \mathrm{~Hz})$ (Fig. 4A, shaded area). It is important to note that the $\mathrm{Ca}^{2+}$ transients to different tetanization protocols were found to be independent of the sequence of application. As depicted in Figure $4 D$, the averaged areas of the fluorescence intensity changes $\left(\mathrm{Area}_{\mathrm{F} / \mathrm{F}_{0}}\right)$ were correlated linearly, to both the duration of tetanic $100 \mathrm{~Hz}$ stimulation and the pulse width that we used [correlation coefficients of 0.99 ; data of pulse width $0.2 \mathrm{msec}$ (data not shown)]. The Area $_{\mathrm{F} / \mathrm{F}_{0}}$ of the tetanus of four $\times$ two pulses was comparable to the 400 msec tetanus $(100$ $\mathrm{Hz}$ ). This finding corresponds very well with the duration of potentiation obtained with these stimulation protocols in the extracellular experiments (Fig. 2A-D) (additional data not shown).

Although these data provide only a momentary and localized image of the $\left[\mathrm{Ca}^{2+}\right]_{\mathrm{i}}$ dynamics occurring in the dendritic regions, they support the hypothesis that the intradendritic level of $\mathrm{Ca}^{2+}$ is closely correlated to the type and duration of tetanization. Next, we examined by confocal laser scanning microscopy whether the elevation of $\left[\mathrm{Ca}^{2+}\right]_{i}$ after weak tetanic stimulation can be impaired by an inhibition of class I mGluRs, as implied by the coupling of class I mGluRs to $\mathrm{IP}_{3}$-sensitive ICSs and suggested by the action of 4-CPG in the weak potentiation paradigms (Fig. $2 B-D$ ). As shown in Figure $4 F$, bath application of the same concentration of 4-CPG $(50 \mu \mathrm{M})$ led to a significant reduction of Area $_{\mathrm{F} / \mathrm{F}_{0}}$ to $67 \%$ of control $(n=6 ; p<0.05)$. This reduction was predominantly caused by a slower rise and earlier decay of $\left[\mathrm{Ca}^{2+}\right]_{\mathrm{i}}$ (Fig. $4 E$ ). The effect of $4-\mathrm{CPG}$ was reversible in all neurons tested (Fig. 4E, wash out).

The results of the $\mathrm{Ca}^{2+}$ imaging studies led us to conclude that weak tetanization paradigms that evoked a weak or moderate $\left[\mathrm{Ca}^{2+}\right]_{\mathrm{i}}$ response could be affected by a mGluR class I antagonist. We thus investigated whether a blockade of other $\mathrm{Ca}^{2+}$ sources during strong tetanization, such as the entry of $\mathrm{Ca}^{2+}$ through VDCCs, could enable class I mGluRs to affect LTP. To examine this hypothesis, we coapplied the L-type VDCC antagonist nimodipine together with the mGluR antagonists MCPG and 
A
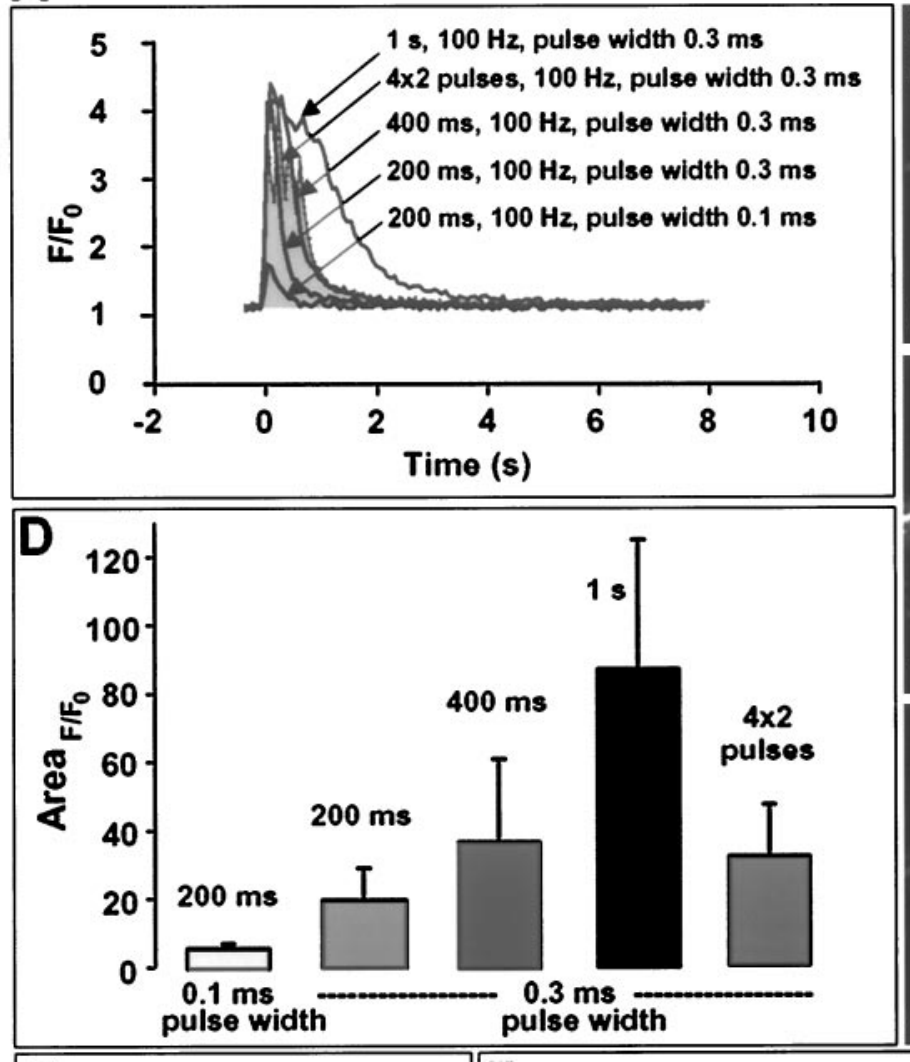

B
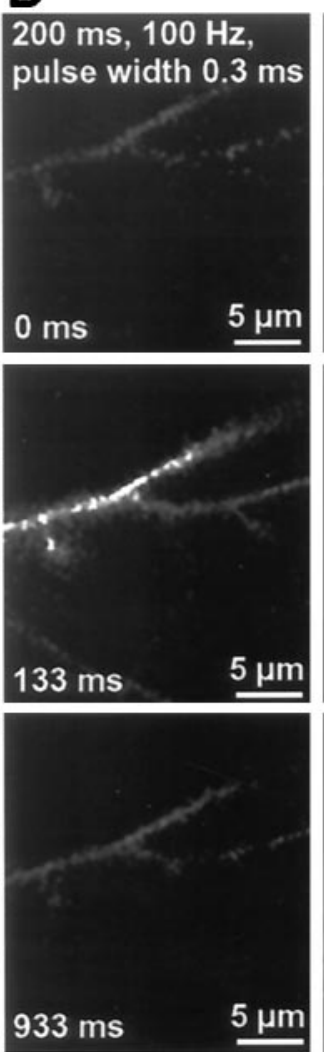

C
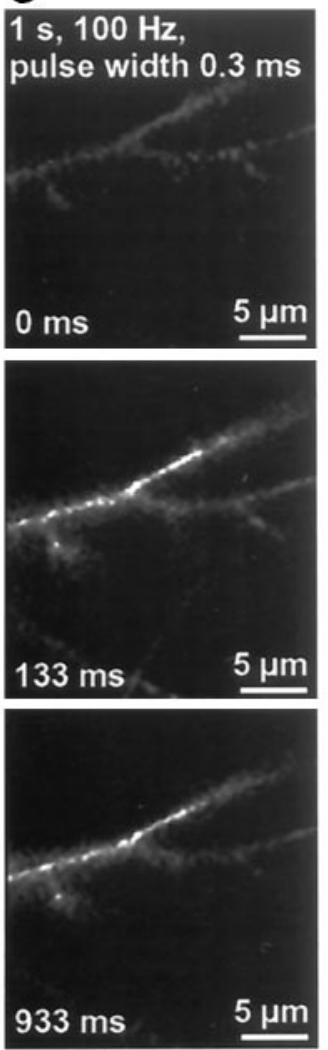
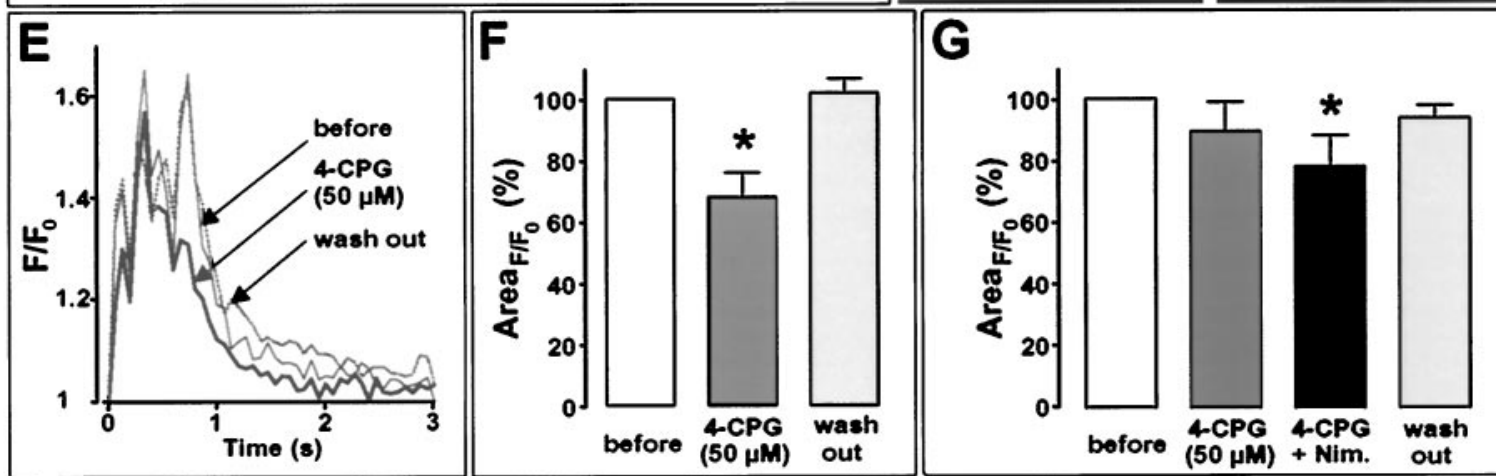

Figure 4. $\mathrm{Ca}^{2+}$ imaging of the rise of $\left[\mathrm{Ca}^{2+}\right]_{\mathrm{i}}$ in the dendritic tree of CA1 neurons (filled with the $\mathrm{Ca}^{2+}$-sensitive dye Calcium Green-1) on stimulation with different tetanization protocols and bath application of the mGluR class I antagonist 4-CPG (50 $\mu \mathrm{M})$ and the L-type VDCC antagonist nimodipine $(10 \mu \mathrm{M}) . A$, Averaged $\mathrm{Ca}^{2+}$ response curves (transients) of seven neurons to a single set of tetanization paradigms. The $\mathrm{Ca}^{2+}$ transients of four dendritic regions were averaged. The tetanization protocols corresponding to the curves are indicated by an arrow. An increasing duration of the $100 \mathrm{~Hz}$ stimulation led initially to an increment of the peak amplitude, but after reaching a maximum amplitude the high $\mathrm{Ca}^{2+}$ level is maintained, followed by a slower decay (1 sec train). Application of the standard weak tetanization paradigm of four bursts of two pulses at $100 \mathrm{~Hz}$ (200 msec interburst interval) triggered a $\left[\mathrm{Ca}^{2+}\right]_{\mathrm{i}}$ rise that resembled the $\left[\mathrm{Ca}^{2+}\right]_{\mathrm{i}}$ responses obtained with the common $100 \mathrm{~Hz}$ protocols but was superimposed by steep pinnacles that were synchronized with the interburst interval of $200 \mathrm{msec}(5 \mathrm{~Hz})$ (shaded area). $B$, $C$, Representative images of the Ca ${ }^{2+}$ response of one neuron. The $\mathrm{Ca} 2+$ response to a weak $(200 \mathrm{msec})(B)$ and a strong tetanization $(1 \mathrm{sec})(C)$ is illustrated. The examples were taken at the onset of tetanization (top images), at the maximum of $\left[\mathrm{Ca}^{2+}\right]_{\mathrm{i}}$ elevation (middle), and during the decay phase of the response (bottom). Note the clear difference in the $\mathrm{Ca}^{2+}$ level during the decay of response at $933 \mathrm{msec}$ (bottom traces). D, As indicated by the averaged areas of the fluorescence intensity changes $\left(\right.$ Area $\left.{ }_{F / F_{0}}\right)$, the rise of $\left[\mathrm{Ca}^{2+}\right]_{\mathrm{i}}$ was closely correlated to both the duration of tetanic $100 \mathrm{~Hz}$ stimulation and the pulse width that was used (correlation coefficients of 0.99 ; data not shown of pulse width $0.2 \mathrm{msec})$. The area below the $F / F_{0}$ curves was calculated as Area $_{F / F_{0}}=\int_{\mathrm{B}}\left(F / F_{0}-1\right) \mathrm{dt} ; B=[0 \mathrm{sec}$, $8 \mathrm{sec}] . E, F$, After a tetanization of four $\times$ two pulses, bath application of $4-\mathrm{CPG}(50 \mu \mathrm{M})$ led to a significant reduction $(p<0.05)$ of $\mathrm{Area}_{F / F_{0}}$ to $67 \%$ $(F)$, which was caused predominantly by a slower rise and earlier decay of $\left[\mathrm{Ca}^{2+}\right]_{\mathrm{i}}$. Note that the effect of 4-CPG was reversible (wash out line in $E$ ). $G$, Only the coapplication of 4-CPG and nimodipine caused a significant reduction of $A_{r e a} F_{F / F_{0}}(78 \% ; p<0.05)$ during strong tetanization $(1 \mathrm{sec}, 100 \mathrm{~Hz})$. The application of 4-CPG alone had no effect.

4-CPG during strong tetanization. Nimodipine $(10 \mu \mathrm{M} ; n=8)$ applied on its own during tetanization did not modify the potentiation in comparison to control experiments $(n=6$; data not shown). However, the coapplication of nimodipine $(10 \mu \mathrm{M})$ and
MCPG (400 $\mu \mathrm{M})$ led to a marked reduction of LTP (Fig. 5A). The impairment of LTP became significant 150 min after tetanization and resulted in a diminished potentiation of $127 \pm 8 \% 240 \mathrm{~min}$ after LTP induction $(n=7)$ as compared with $179 \pm 15 \%$ in the 

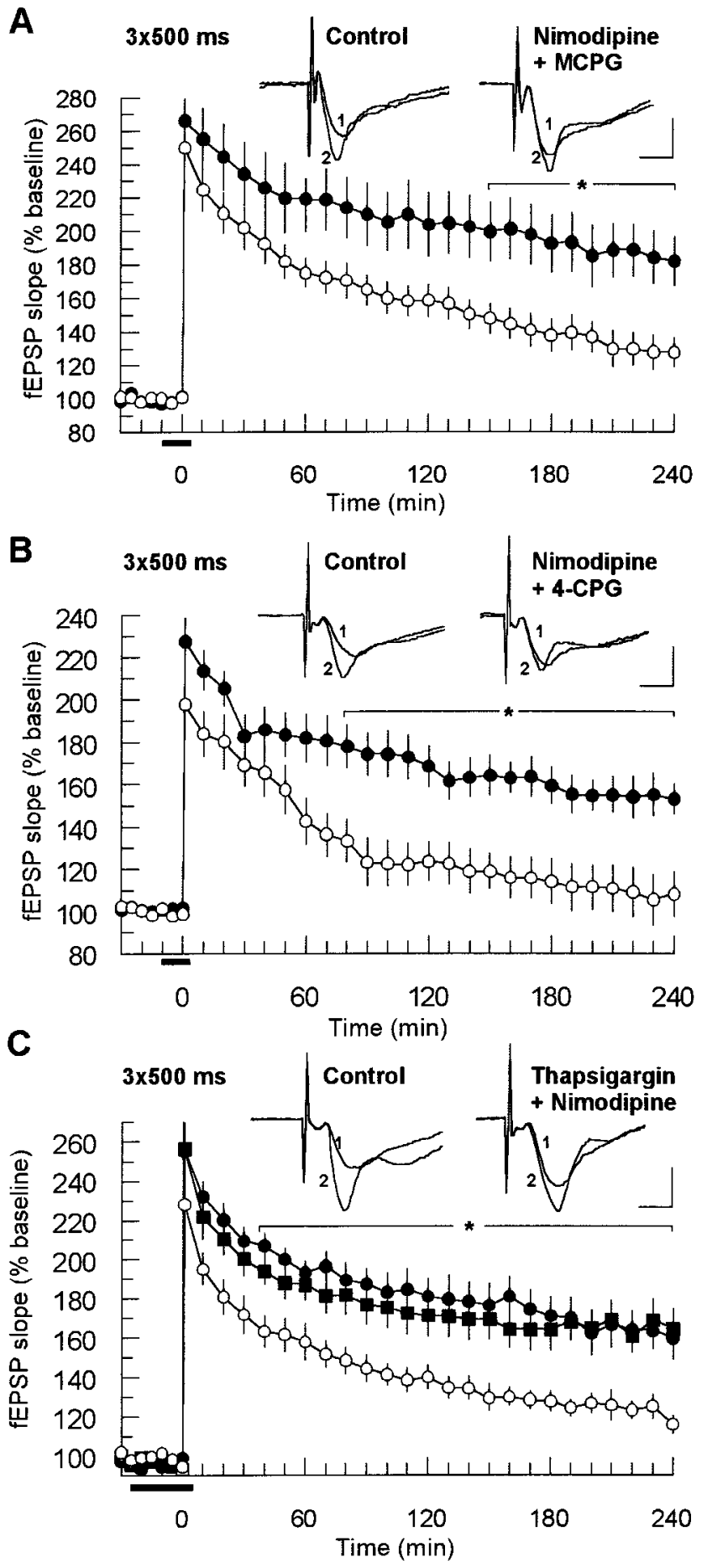

Figure 5. Coapplication of mGluR class I antagonists and the L-type calcium channel antagonist nimodipine impaired LTP evoked by a strong tetanization protocol. $A$, MCPG $(400 \mu \mathrm{M})$ affected the potentiation when nimodipine $(10 \mu \mathrm{M})$ was coapplied. The reduction became significant 150 min after tetanization $(p<0.05 ; n=7)$. The control application of nimodipine alone $(n=8)$ had no effect on LTP. $B$, Similarly, coapplication of 4-CPG $(100 \mu \mathrm{M})$ and nimodipine resulted in a significant impairment of LTP starting 80 min after tetanization $(p<0.05 ; n=7)$, whereas nimodipine by itself was not effective $(n=8)$. $C$, Application of thapsigargin $(6 \mu \mathrm{M})$ had the same effect as mGluR class I antagonists if coapplied with nimodipine $(\bigcirc, p<0.05 ; n=7)$. The application of nimodipine $(\boldsymbol{\bullet}, n=7)$ and thapsigargin $(\boldsymbol{\square}, n=6)$ alone had no influence on LTP. See Figure 2 for further explanation. control group $(n=7 ; p<0.05)$. Similar to the experiments with the weak tetanization, the initial potentiation was unaffected, showing that post-tetanic potentiation was not modified. The effects of $100 \mu \mathrm{M} 4-\mathrm{CPG}$ coapplied with nimodipine $(10 \mu \mathrm{M})(n=$ 7) resembled the $\mathrm{MCPG} /$ nimodipine experiments. Although the initial potentiation was not influenced, the 4-CPG/nimodipine group displayed a faster rundown of potentiation, which became statistically distinguishable from controls $80 \mathrm{~min}$ after tetanus (Fig. 5B). After $240 \mathrm{~min}$, the potentiation had nearly declined to baseline $(108 \pm 12 \%)$ as compared with controls $(152 \pm 7 \%)$.

Because the electrophysiological studies showed that nimodipine may enable 4-CPG to affect LTP induced by strong tetanization, we tested the coapplication of 4-CPG and nimodipine in confocal imaging experiments. 4-CPG, bath-applied in the strong tetanization protocol (1 sec, $100 \mathrm{~Hz}$ ), had no effect (Fig. 4G). However, coapplication of 4-CPG with nimodipine $(10 \mu \mathrm{M})$ caused a significant reduction of Area $_{\mathrm{F} / \mathrm{F}_{0}}$ to $78 \%$ of control $(n=$ $5 ; p<0.05)$.

These results support our hypothesis that the efficiency of mGluR class I antagonists depends on the level of $\left[\mathrm{Ca}^{2+}\right]_{\mathrm{i}}$. During strong tetanization, the $\mathrm{Ca}^{2+}$ influx through NMDARs is significantly augmented by $\mathrm{Ca}^{2+}$ entering the neuron through L-type VDCCs. The high $\mathrm{Ca}^{2+}$ level originating from these two sources overrides the functional role of $\mathrm{Ca}^{2+}$ release from $\mathrm{IP}_{3}$ sensitive ICSs. If MCPG and 4-CPG block release of $\mathrm{Ca}^{2+}$ from ICSs, then depleting these stores by the $\mathrm{Ca}^{2+}$-ATPase inhibitor thapsigargin should lead to a similar effect in the nimodipine/ strong tetanization paradigm.

As shown in Figure $5 C$, the application of thapsigargin $(6 \mu \mathrm{M}$; $n=6)$ or nimodipine $(10 \mu \mathrm{M} ; n=7)$ had no independent effect on robust LTP, which was induced by strong tetanization (initial values: $256 \pm 12 \%$ and $255 \pm 8 \%$, respectively; 240 min values: $164 \pm 10 \%$ and $159 \pm 11 \%)$. However, coapplication of the two drugs $(n=7)$ caused a severe impairment of potentiation that declined from $228 \pm 12 \%$ initially to $115 \pm 4 \%$ after $240 \mathrm{~min}$ (controls: $256 \pm 12 \%$ and $164 \pm 10 \%$, respectively; $p<0.05$ ).

Therefore, the mGluR antagonists MCPG and 4-CPG and the $\mathrm{Ca}^{2+}$ store depletor thapsigargin only affected a robust LTP if the intracellular $\mathrm{Ca}^{2+}$ level during the tetanus was artificially lowered by blocking the $\mathrm{Ca}^{2+}$ entry through L-type VDCCs.

\section{DISCUSSION}

The presented results demonstrate that the role of mGluRs in LTP is contingent on the tetanization paradigm that is used. The stronger the tetanization, the less potent were the mGluR antagonists MCPG and 4-CPG in affecting the time course of the resulting potentiation. MCPG has been characterized as a competitive antagonist of class I and class II mGluRs, whereas 4-CPG displays a selectivity toward class I mGluRs and only weak activity on mGluRs of class II (Davies et al., 1995; Sekiyama et al., 1996). Because in most of our experiments the results obtained with the two antagonists were very similar, the effects of these compounds on LTP may be assigned to an action on class I mGluRs. This is consistent with the findings of other laboratories that excitatory postsynaptic mGluR actions in the CA1 region are mediated by activation of class I receptors (Davies et al., 1995; Gereau and Conn, 1995) and that agonists of class I mGluRs may facilitate the induction of LTP or induce a potentiation on their own [McGuinness et al., 1991; Otani and Ben-Ari, 1991; Ben-Ari et al., 1992; Bortolotto and Collingridge, 1992, 1995; ManahanVaughan and Reymann, 1995, 1996; Breakwell et al., 1996; O'Leary and O'Connor, 1997 (but see Brown and Reymann, 
1995)]. Both subtypes of class I receptors, mGluR1 and mGluR5, are found in the CA1 subfield as shown by in situ hybridization and immunohistochemical studies [Petralia et al., 1997 (for further references, see Luján et al., 1996)].

Our findings shed new light on the controversy concerning the functional role of mGluRs in LTP and the contradictory data that have been obtained with MCPG. If the studies that dealt with the action of MCPG on hippocampal LTP are classified according to the type and strength of tetanization applied, then the resulting picture is largely consistent with the conclusions drawn from our experiments. Whereas in all studies using a "strong" tetanization (theta-burst stimulation or repetitive $100 \mathrm{~Hz} / 1 \mathrm{sec}$ protocols) MCPG failed to block LTP (Manzoni et al., 1994; Selig et al., 1995; Thomas and O'Dell, 1995), a single $100 \mathrm{~Hz}$ stimulation of 1 sec duration appears to mark a critical threshold where the involvement of mGluRs depends on certain (as yet unknown) experimental conditions (Bashir et al., 1993; Chinestra et al., 1993; Bortolotto et al., 1994; Thomas and O'Dell, 1995). In contrast, all tetanization paradigms that used single $100 \mathrm{~Hz}$ protocols $<1 \mathrm{sec}$ resulted in a potentiation that was dependent on a mGluR class I activation. In our experiments, the potentiation became susceptible to the action of MCPG and 4-CPG as soon the duration of the tetanus was reduced to $400 \mathrm{msec}$.

In our search for the basic mechanism that may underlie the tetanization strength-dependent efficiency of MCPG and 4-CPG, we focused on changes of the intracellular $\mathrm{Ca}^{2+}$ level after activation of class I mGluRs during tetanization. It is generally accepted that the induction of LTP in the CA1 area requires an elevation of the free, intracellular $\mathrm{Ca}^{2+}$ concentration in the postsynaptic neuron (Lynch et al., 1983; Malenka et al., 1988). In addition to $\mathrm{Ca}^{2+}$ influx through NMDARs (Collingridge et al., 1983; Malenka, 1994), two other important $\mathrm{Ca}^{2+}$ sources can feed the rise of $\left[\mathrm{Ca}^{2+}\right]_{i}$ during tetanization: $\mathrm{Ca}^{2+}$ influx through VDCCs and the release of $\mathrm{Ca}^{2+}$ from $\mathrm{IP}_{3^{-}}$and ryanodinesensitive ICSs (Thastrup et al., 1990; Berridge, 1993; Frenguelli et al., 1996).

Activation of VDCCs appears to be critically involved in the generation of LTP by strong tetanization at $200 \mathrm{~Hz}$ and higher frequencies (Grover and Teyler, 1990). In contrast, the widely used strong $100 \mathrm{~Hz}$ paradigms evoke a potentiation that contains a smaller, inconspicuous VDCC-dependent component, as shown by Grover and Teyler (1994), and confirmed in our experiments by the lack of significant effects of nimodipine on potentiation.

$\mathrm{Ca}^{2+}$ release from ICSs (Thastrup et al., 1990; Berridge, 1993) seems to play a decisive role in LTP induction under certain conditions. Harvey and Collingridge (1992) reported a block of LTP if the selective $\mathrm{Ca}^{2+}$-ATPase inhibitor thapsigargin was applied during tetanization, but not if given $30 \mathrm{~min}$ afterward. In previous experiments in our laboratory, we found that bath application of thapsigargin during tetanization did not affect a robust LTP generated by a triple $100 \mathrm{~Hz}$ tetanus, but impaired a weaker potentiation induced by a single $100 \mathrm{~Hz}$ train of $400 \mathrm{msec}$ duration (Behnisch and Reymann, 1995).

In this study, we did not see an effect of MCPG or 4-CPG on potentiation induced by a strong $100 \mathrm{~Hz}$ protocol, which is in accordance with the findings of other groups (Chinestra et al., 1993; Izumi and Zorumski, 1994; Manzoni et al., 1994; Thomas and O'Dell, 1995; Selig et al., 1995). However, coapplication of MCPG or 4-CPG with nimodipine had detrimental consequences on potentiation. Thus, inhibition of the $\mathrm{Ca}^{2+}$ influx through VDCCs during tetanization did not result in overt changes of LTP, but the potentiation became dependent on activation of class I mGluRs. Because thapsigargin mimicked exactly the action of MCPG and 4-CPG in impairing a robust LTP only when L-type VDCCs were additionally inhibited by nimodipine, we concluded that both antagonists acted via an inhibition of the $\mathrm{IP}_{3}$-mediated $\mathrm{Ca}^{2+}$-release from ICSs (Thastrup et al., 1990; Berridge, 1993). These findings indicated that the involvement of class I mGluRs in synaptic plasticity depends on $\left[\mathrm{Ca}^{2+}\right]_{i}$ attained during tetanization and the interaction between VDCCs and ICSs.

Although the confocal $\left[\mathrm{Ca}^{2+}\right]_{\mathrm{i}}$ measurements did not resolve the contribution of the different $\mathrm{Ca}^{2+}$ sources to the tetanic $\left[\mathrm{Ca}^{2+}\right]_{\mathrm{i}}$ rise, they gave clear evidence of a tight correlation between $\left[\mathrm{Ca}^{2+}\right]_{\mathrm{i}}$ and the strength of tetanization. In addition, they supported a different functional role for mGluR-triggered $\mathrm{Ca}^{2+}$ release from $\mathrm{IP}_{3}$-sensitive ICSs during weak and strong tetanic stimulation. Under our experimental conditions, Area $\mathrm{F}_{\mathrm{F}} \mathrm{F}_{0}$ was not only monotonic but linearly correlated to the pulse width and duration of tetanization. However, the shape of $\left[\mathrm{Ca}^{2+}\right]_{i}$ responses and the resulting Area $\mathrm{F}_{\mathrm{F}} \mathrm{F}_{0}$ might have been influenced by methodical constraints such as saturation of the $\mathrm{Ca}^{2+}$ dye Calcium Green-1 ( $\left.\mathrm{K}_{\mathrm{d}} 189 \mathrm{nM}\right)$. The $\mathrm{Ca}^{2+}$ kinetics that we obtained after tetanic stimulation of increasing duration and pulse width extend the previous findings of Regehr and Tank (1992), who described $\mathrm{Ca}^{2+}$ accumulations in response to tetanization $(100 \mathrm{~Hz}$ for $1 \mathrm{sec})$ with increasing stimulation intensity. Malenka et al. (1992) reported that the $\left[\mathrm{Ca}^{2+}\right]_{\mathrm{i}}$ surge within the initial 2 sec after onset of potentiation determines the resulting type and the properties of plasticity. In our study, the often used $100 \mathrm{~Hz} / 1$ sec stimulation led to intradendritic $\left[\mathrm{Ca}^{2+}\right]_{\mathrm{i}}$ kinetics with a steep increase, a maximum of $\sim 1000 \mathrm{msec}$ and an exponential decay resulting in $\left[\mathrm{Ca}^{2+}\right]_{\mathrm{i}}$, which was still elevated after 2 sec. The finding that $4-\mathrm{CPG}$ attenuates the tetanus-induced $\left[\mathrm{Ca}^{2+}\right]_{\mathrm{i}}$ surge is consistent with the studies of Frenguelli et al. (1993), which described a similar effect for $\mathrm{MCPG}$, and in accordance with Alford et al. (1993), who reported that blockade of $\mathrm{Ca}^{2+}$ release from ICSs may cause a considerable reduction of $\left[\mathrm{Ca}^{2+}\right]_{\mathrm{i}}$ in CA1 pyramidal neurons. However, in our hands, 4-CPG reduced only the $\left[\mathrm{Ca}^{2+}\right]_{\mathrm{i}}$ elevation induced by weak but not by strong tetanization.

Putting all of these facts together, we hypothesize that the three main $\mathrm{Ca}^{2+}$ sources interfere with each other during LTP induction, as schematically outlined in Figure 6. During weak tetanization (Fig. $6 A_{1}$ ), the characteristics of the attained depolarization do not allow the L-type VDCCs to contribute significantly to the $\mathrm{Ca}^{2+}$ influx required for LTP induction. The $\mathrm{Ca}^{2+}$ entry is therefore accomplished predominantly via NMDARs. The moderate intracellular $\mathrm{Ca}^{2+}$ level and $\mathrm{IP}_{3}$ liberated by activation of class $\mathrm{I}$ mGluRs trigger the release of $\mathrm{Ca}^{2+}$ from $\mathrm{IP}_{3}$-sensitive stores resulting in an amplification and prolongation of the $\mathrm{Ca}^{2+}$ signal beyond the threshold for LTP induction, as supported by computational studies (Schiegg et al., 1995).

In contrast, during strong tetanization (Fig. $6 B_{1}$ ) leading to a sustained depolarization, the contribution of VDCCs to the $\left[\mathrm{Ca}^{2+}\right]_{\mathrm{i}}$ surge is increased, i.e., $\mathrm{Ca}^{2+}$ enters the neuron via NMDARs and VDCCs. The corresponding high $\left[\mathrm{Ca}^{2+}\right]_{i}$ may interfere via two different mechanisms with the class I-triggered $\mathrm{Ca}^{2+}$ release. (1) The high $\left[\mathrm{Ca}^{2+}\right]_{\mathrm{i}}$ could functionally override the contribution of the surplus $\mathrm{Ca}^{2+}$ from ICSs, i.e., the threshold for LTP induction (Lisman, 1989; Artola and Singer, 1993; Cummings et al., 1996; Neveu and Zucker, 1996; Tsumoto and Yasuda, 1996) can be achieved solely by activation of NMDARs and VDCCs. (2) The high cytosolic $\mathrm{Ca}^{2+}$ concentration can decrease the $\mathrm{Ca}^{2+}$ release from $\mathrm{IP}_{3}$-sensitive stores because of the bell- 
control conditions

$A_{1}$

HH

$\| t|t|$

weak tetanus

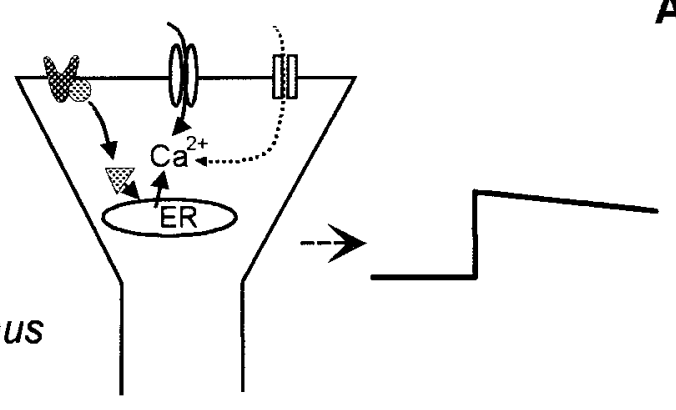

experimental treatment

$A_{2}$

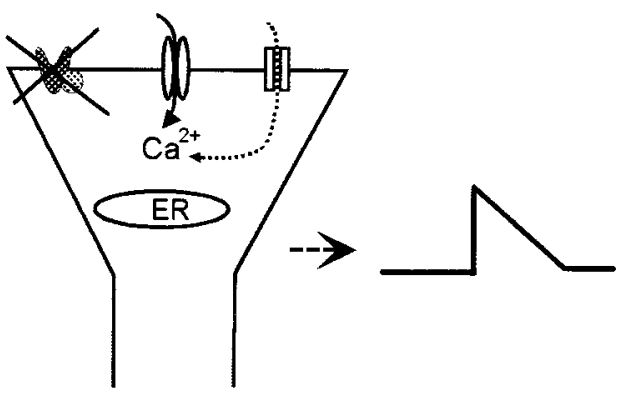

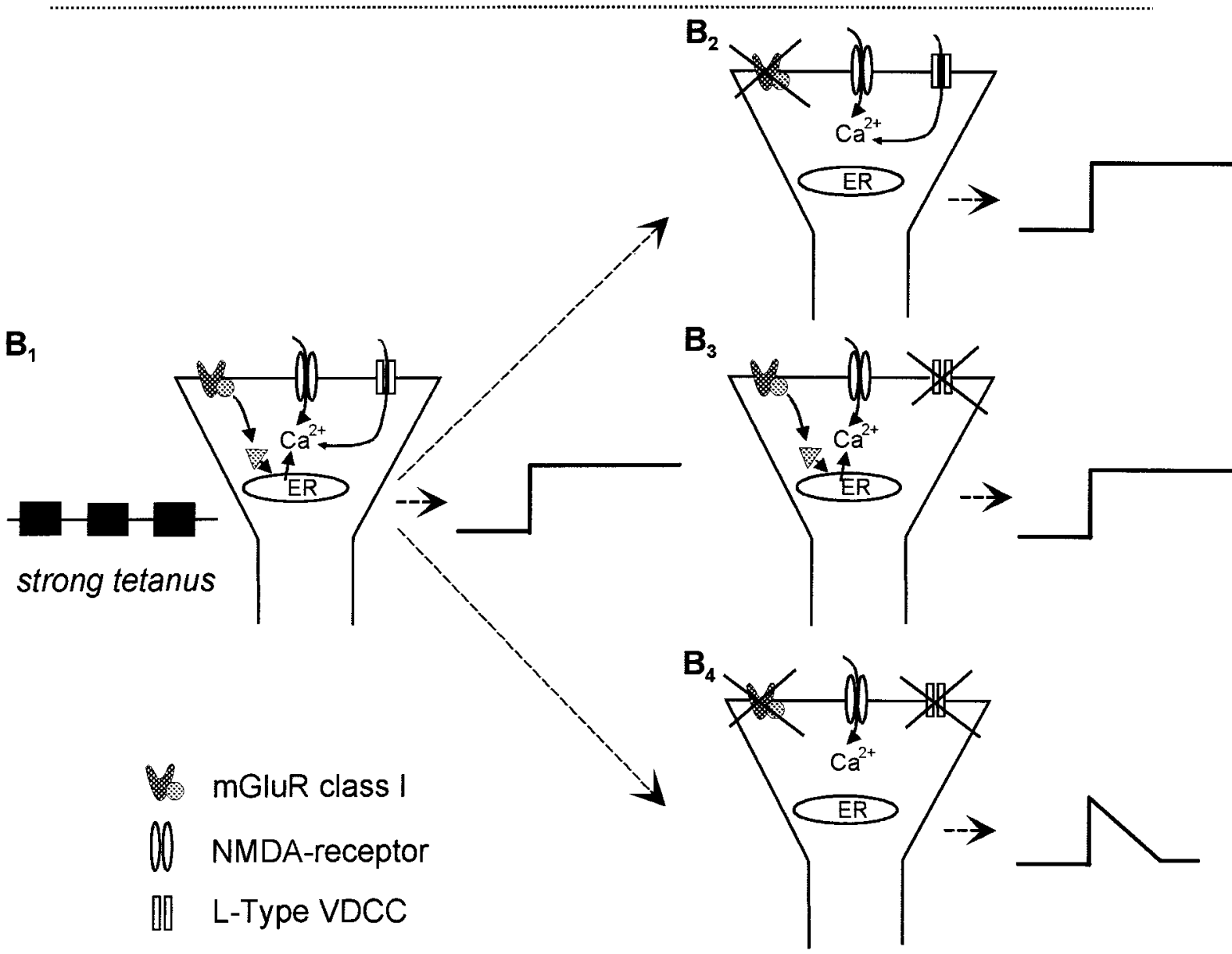

$$
\mathrm{LTP}=\mathrm{Ca}^{2+} \uparrow_{\mathrm{NMDA}}+\left(\mathrm{Ca}^{2+} \uparrow_{\text {mGluR class } 1} \text { or } \mathrm{Ca}^{2+} \uparrow_{\mathrm{L}-\mathrm{Type} \text { VDCC }}\right)
$$

Figure 6. Scheme of the role of the three main $\mathrm{Ca}^{2+}$ sources during LTP induction in dependence of the tetanization strength. The final $\left[\mathrm{Ca}^{2+}\right]_{\mathrm{i}}$ necessary for induction of LTP is determined by two factors, the NMDARs and an additional source provided by either VDCCs or the Ca ${ }^{2+}$ release from ICSs after activation of class I mGluRs. Top scheme, $A_{1}$, During a weak, single tetanization the rise of $\left[\mathrm{Ca}^{2+}\right]_{\mathrm{i}}$ is fed by the activation of NMDARs and class I mGluRs, whereas the contribution of L-type VDCCs is negligible under these conditions. Thus, application of class I antagonists causes an impairment of LTP $\left(A_{2}\right)$. Bottom scheme, $B_{1}$, A strong tetanization paradigm leads to a sustained depolarization enabling the Ca ${ }^{2+}$ entry via NMDARs and VDCCs, as well as to the release of $\mathrm{Ca}^{2+}$ from ICSs. $B_{2}$, The additional $\mathrm{Ca}^{2+}$ that is provided by the release from ICSs via liberation of IP ${ }_{3}$ on class I mGluR activation is not required for LTP induction. $B_{3}$, Blockade of VDCCs is counterbalanced by the class I mGluR-triggered Ca ${ }^{2+}$ release from ICSs. $B_{4}$, Concomitant inhibition of class I mGluRs and VDCCs results in a decremental potentiation. 
shaped $\mathrm{Ca}^{2+}$ sensitivity of $\mathrm{IP}_{3}$ channels (Bootman and Berridge, 1995).

The findings of the present study and the available experimental evidence lead us to hypothesize that class I mGluRs have a particular function in LTP. During weak and moderate tetanization, they amplify the initial $\left[\mathrm{Ca}^{2+}\right]_{\mathrm{i}}$ surge that originates from $\mathrm{Ca}^{2+}$ influx through NMDARs, beyond the threshold for LTP induction; i.e., by instigating the $\mathrm{Ca}^{2+}$ release from $\mathrm{IP}_{3}$-sensitive ICSs they enable an NMDA-dependent input-specific LTP. Therefore, at moderate levels of synaptic activation, class I mGluRs may function as threshold boosters in input-specific Hebb-type plasticity.

\section{REFERENCES}

Aiba A, Chen C, Herrup K, Rosenmund C, Stevens CF, Tonegawa S (1994) Reduced hippocampal long-term potentiation and contextspecific deficit in associative learning in mGluR1 mutant mice. Cell 79:365-375.

Alford S, Frenguelli BG, Schofield JG, Collingridge GL (1993) Characterization of $\mathrm{Ca}^{2+}$ signals induced in hippocampal CA1 neurones by the synaptic activation of NMDA receptors. J Physiol (Lond) 469:693-716.

Artola A, Singer W (1993) Long-term depression of excitatory synaptic transmission and its relationship to long-term potentiation. Trends Neurosci 16:480-487.

Bashir ZI, Bortolotto ZA, Davies CH, Beretta N, Irving AJ, Sea AJ, Henley JM, Jane DE, Watkins JC, Collingridge GL (1993) Induction of LTP in the hippocampus needs synaptic activation of glutamate metabotropic receptors. Nature 363:347-350.

Behnisch T, Reymann KG (1995) Thapsigargin blocks long-term potentiation induced by weak, but not strong tetanization in rat hippocampal CA1 neurons. Neurosci Lett 192:185-188.

Ben-Ari Y, Aniksztejn L, Bregestowski P (1992) Protein kinase-C modulation of NMDA currents: an important link for LTP induction. Trends Neurosci 15:333-339.

Berridge MJ (1993) Inositol trisphosphate and calcium signalling. Nature 361:315-325.

Bliss TVP, Collingridge GL (1993) A synaptic model of memory: longterm potentiation in the hippocampus. Nature 361:31-39.

Bootman MD, Berridge MJ (1995) The elemental principles of calcium signaling. Cell 83:675-678.

Bortolotto ZA, Collingridge GL (1992) Activation of glutamate metabotropic receptors induces long-term potentiation. Eur J Pharmacol 214:297-298.

Bortolotto ZA, Collingridge GL (1995) On the mechanism of long-term potentiation induced by (1S,3R)-1-aminocyclopentane-1,3-dicarboxylic acid (ACPD) in rat hippocampal slices. Neuropharmacology 34:1003-1014.

Bortolotto ZA, Bashir ZI, Davies CH, Collingridge GL (1994) A molecular switch activated by metabotropic glutamate receptors regulates induction of long-term potentiation. Nature 368:740-743.

Breakwell NA, Rowan MJ, Anwyl R (1996) Metabotropic glutamate receptor dependent EPSP and EPSP-spike potentiation in area CA1 of the submerged rat hippocampal slice. J Neurophysiol 76:3126-3135.

Brown RE, Reymann KG (1995) Class I metabotropic glutamate receptor agonists do not facilitate the induction of long-term potentiation in the dentate gyrus of the rat in vitro. Neurosci Lett 202:73-76.

Brown RE, Rabe H, Reymann KG (1994) (RS)- $\alpha$-methyl-4carboxyphenylglycine (MCPG) does not block theta burst-induced long-term potentiation in area CA1 of rat hippocampal slices. Neurosci Lett 170:17-21.

Chinestra P, Aniksztejn L, Diabira D, Ben-Ari Y (1993) (RS)-alphamethyl-4-carboxyphenylglycine neither prevents induction of LTP nor antagonizes metabotropic glutamate receptors in CA1 hippocampal neurons. J Neurophysiol 70:2684-2689.

Collingridge GL, Kehl SJ, McLennon H (1983) Excitatory amino acids in synaptic transmission in the Schaffer collateral-commissural pathway of the rat hippocampus. J Physiol (Lond) 334:33-46.

Conn PJ, Pin J-P (1997) Pharmacology and function of metabotropic glutamate receptors. Annu Rev Pharmacol Toxicol 37:205-237.

Conquet F, Bashir ZI, Davies CH, Daniel H, Ferraguti F, Bordi F, Franzbacon K, Reggiani A, Matarese V, Conde F, Collingridge GL,
Crepel F (1994) Motor deficit and impairment of synaptic plasticity in mice lacking mGluR1. Nature 372:237-243.

Cummings JA, Mulkey RM, Nicoll RA, Malenka RC (1996) $\mathrm{Ca}^{2+}$ signaling requirements for long-term depression in the hippocampus. Neuron 16:825-833.

Davies CH, Clarke VRJ, Jane DE, Collingridge GL (1995) Pharmacology of postsynaptic metabotropic glutamate receptors in rat hippocampal CA1 pyramidal neurons. Br J Pharmacol 116:1859-1869.

Frenguelli BG, Potier B, Slater NT, Alford S, Collingridge GL (1993) Metabotropic glutamate receptors and calcium signalling in dendrites of hippocampal CA1 neurones. Neuropharmacology 32:1229-1237.

Frenguelli BG, Irving AJ, Collingridge GL (1996) $\mathrm{Ca}^{2+}$ stores and hippocampal synaptic plasticity. Semin Neurosci 8:301-309.

Gereau RW, Conn PJ (1995) Roles of metabotropic glutamate receptor subtypes in regulation of hippocampal CA1 pyramidal cell excitability. J Neurophysiol 74:122-129.

Grover LM, Teyler TJ (1990) Two components of long-term potentiation induced by different patterns of activation. Nature 347:477-479.

Grover LM, Teyler TJ (1994) Activation of NMDA receptors by low and high frequency orthodromic stimulation, and their contribution to induction of long-term potentiation. Synapse 16:66-75.

Harvey J, Collingridge GL (1992) Thapsigargin blocks the induction of long-term potentiation in rat hippocampal slices. Neurosci Lett 139:197-200.

Izumi Y, Zorumski CF (1994) Developmental changes in the effects of metabotropic glutamate receptor antagonists on CA1 long-term potentiation in rat hippocampal slices. Neurosci Lett 176:89-92.

Jaffe DB, Brown TH (1994) Metabotropic glutamate receptor activation induces calcium waves within hippocampal dendrites. J Neurophysiol 72:471-474.

Kauer JA, Malenka RC, Nicoll RA (1988) NMDA application potentiates synaptic transmission in the hippocampus. Nature 334:250-252.

Lisman J (1989) A mechanism for the Hebb and the anti-Hebb processes underlying learning and memory. Proc Natl Acad Sci USA 86:9574-9578.

Little Z, Grover LM, Teyler TJ (1995) Metabotropic glutamate receptor antagonist, (R,S)-alpha-methyl-4-carboxyphenylglycine, blocks two distinct forms of long-term potentiation in area CA1 of rat hippocampus. Neurosci Lett 201:73-76.

Lu YM, Jia Z, Janus C, Henderson JT, Gerlai R, Wojtowicz JM, Roder JC (1997) Mice lacking metabotropic glutamate receptor 5 show impaired learning and reduced CA1 long-term potentiation (LTP) but normal CA3 LTP. J Neurosci 17:5196-5205.

Luján R, Nusser Z, Roberts JDB, Shigemoto R, Somogyi P (1996) Perisynaptic location of metabotropic glutamate receptors mGluR1 and mGluR5 on dendrites and dendritic spines in the rat hippocampus. Eur J Neurosci 8:1488-1500.

Lynch GS, Larson J, Kelso S, Barrionuevo G, Schottler F (1983) Intracellular injections of EGTA block the induction of hippocampal longterm potentiation. Nature 305:719-721.

Malenka RC (1994) Synaptic plasticity in the hippocampus, LTP and LTD. Cell 78:535-538.

Malenka RC, Kauer JA, Zucker RJ, Nicoll RJ (1988) Post-synaptic calcium is sufficient for potentiation of hippocampal synaptic transmission. Science 242:81-84.

Malenka RC, Lancaster B, Zucker RS (1992) Temporal limits on the rise in postsynaptic calcium required for the induction of long-term potentiation. Neuron 9:121-128.

Manahan-Vaughan D, Reymann KG (1995) 1S,3R-ACPD dosedependently induces a slow-onset potentiation in the rat hippocampal CA1 region in vivo. Neuropharmacology 34:1103-1105.

Manahan-Vaughan D, Reymann KG (1996) Metabotropic glutamate receptor subtype agonists facilitate LTP within a distinct time window in the dentate gyrus in vivo. Neuroscience 74:723-731.

Manzoni OJ, Weisskopf MG, Nicoll RA (1994) MCPG antagonizes metabotropic glutamate receptors but not long-term potentiation in the hippocampus. Eur J Neurosci 6:1050-1054.

McGuinness N, Anwyl R, Rowan M (1991) Trans-ACPD enhances long-term potentiation in the hippocampus. Eur $\mathrm{J}$ Pharmacol 19:231-232.

Murphy SN, Miller RJ (1988) A glutamate receptor regulates $\mathrm{Ca}^{2+}$ mobilisation in hippocampal neurones. Proc Natl Acad Sci USA 85:8737-8741.

Nakanishi S (1994) Metabotropic glutamate receptors: synaptic transmission, modulation, and plasticity. Neuron 13:1031-1037. 
Neveu D, Zucker RS (1996) Postsynaptic levels of $\left[\mathrm{Ca}^{2+}\right]_{\mathrm{i}}$ needed to trigger LTD and LTP. Neuron 16:619-629.

O'Leary DM, O'Connor JJ (1997) Potentiation of synaptic transmission in the rat dentate gyrus in vitro by $(S)$-3,5-dihydroxyphenylglycine $((S)$-DHPG). Neurosci Lett 229:29-32.

Otani D, Ben-Ari Y (1991) Metabotropic receptor mediated long-term potentiation in rat hippocampal slices. Eur J Pharmacol 205:325-326.

Petralia RS, Wang Y-X, Singh S, Wu C, Shi L, Wenthold RJ (1997) A monoclonal antibody shows discrete cellular and subcellular localizations of mGluR $1 \alpha$ metabotropic glutamate receptors. J Chem Neuroanat 13:77-93.

Phenna S, Jane SD, Chad JE (1995) Increased perinuclear $\mathrm{Ca}^{2+}$ activity evoked by metabotropic glutamate receptor activation in rat hippocampal neurones. J Physiol (Lond) 486:149-161.

Regehr WG, Tank DW (1992) Calcium concentration dynamics produced by synaptic activation of CA1 hippocampal pyramidal cells. J Neurosci 12:4202-4223.

Richter-Levin G, Errington ML, Maegawa H, Bliss TVP (1994) Activation of metabotropic glutamate receptors is necessary for long-term potentiation in the dentate gyrus and for spatial learning. Neuropharmacology 33:853-857.

Riedel G, Casabona G, Reymann KG (1995) Inhibition of long-term potentiation in the dentate gyrus of freely moving rats by the metabotropic glutamate receptor antagonist MCPG. J Neurosci 15:87-98.
Schiegg A, Gerstner W, Ritz R, van Hemmen JL (1995) Intracellular $\mathrm{Ca}^{2+}$ stores can account for the time course of LTP induction: a model of $\mathrm{Ca}^{2+}$ dynamics in dendritic spines. J Neurophysiol 74:1046-1055.

Sekiyama N, Hayashi Y, Nakanishi S, Jane DE, Tse H-W, Birse EF, Watkins JC (1996) Structure-activity relationships of new agonists and antagonists of different metabotropic glutamate receptor subtypes. Br J Pharmacol 117:1493-1503.

Selig DK, Lee HK, Bear MF, Malenka RC (1995) Re-examination of the effects of MCPG on hippocampal LTP, LTD and depotentiation. J Neurophysiol 74:1075-1082.

Shirasaki T, Harata N, Akaike N (1994) Metabotropic glutamate response in acutely dissociated hippocampal CA1 pyramidal neurones of the rat. J Physiol (Lond) 475:439-453.

Thastrup O, Cullen PJ, Drobak BK, Hanley MR, Dawson AP (1990) Thapsigargin, a tumor promotor, discharges intracellular $\mathrm{Ca}^{2+}$ stores by specific inhibition of the endoplasmatic reticulum $\mathrm{Ca}^{2(+)}$ ATPase. Proc Natl Acad Sci USA 87:2466-2470.

Thomas MJ, O'Dell TJ (1995) The molecular switch hypothesis fails to explain the inconsistent effects of the metabotropic glutamate receptor antagonist MCPG on long-term potentiation. Brain Res 695:45-52.

Tsumoto T, Yasuda H (1996) A switching role of postsynaptic calcium in the induction of long-term potentiation or long-term depression in visual cortex. Semin Neurosci 8:311-319. 